\title{
INICIAÇÃO ESPORTIVA DE VELEJADORES BRASILEIROS: UM ESTUDO QUALITATIVO DIAGNÓSTICO'
}

\author{
MS. MAICK DA SILVEIRA VIANA \\ Mestre em Ciências do Movimento Humano pela Universidade do \\ Estado de Santa Catarina (UDESC) \\ Pesquisador do Laboratório de Psicologia do Esporte e do Exercício (LAPE) \\ (Florianópolis - Santa Catarina - Brasil) \\ e-mail: efisica@gmail.com
}

DR. ALEXANDRO ANDRADE

Professor do Programa de Pós-Graduação em Ciências do Movimento Humano da

Universidade do Estado de Santa Catarina (UDESC)

Coordenador do Laboratório de Psicologia do Esporte e do Exercício (LAPE)

(Florianópolis - Santa Catarina - Brasil)

e-mail: d2aa@udesc.br

MS. RICARDO BRANDT

Mestre em Ciências do Movimento Humano pela Universidade do

Estado de Santa Catarina (UDESC)

Pesquisador do Laboratório de Psicologia do Esporte e do Exercício (LAPE)

(Florianópolis - Santa Catarina - Brasil)

e-mail: ricabrandt@gmail.com

I. Apoio Financeiro: Ministério de Ciência e Tecnologia - MCT / Financiadora de Estudos e Projetos - FINEP / Ministério do Esporte - ME. Chamada Pública MCT/FINEP/ME - Ciência e Tecnologia para o Esporte - 0I/2006. Processo No 01.06.0633.00. 


\section{RESUMO}

Esta pesquisa teve por objetivo investigar a iniciação esportiva de velejadores brasileiros de alto rendimento. Participaram desse estudo treze velejadores de alto nível, participantes do Pré-Panamericano e do Pré-Olímpico de vela. O instrumento utilizado foi uma entrevista semiestruturada. Os resultados mostraram que os atletas tiveram variadas experiências esportivas na infância, além da prática da vela. A iniciação na vela se deu na maioria dos casos por meio da influência da família, que foram ou ainda são velejadores. A prática na iniciação foi considerada prazerosa pela maioria dos velejadores. Alguns relataram que iniciaram cedo nas competições, mas esse fato não pareceu ter prejudicado psicologicamente ou no desenvolvimento esportivo destes ao longo de sua carreira.

PALAVRAS-CHAVE: Esportes; desempenho esportivo; pesquisa qualitativa; entrevista.

\section{INTRODUÇÃO}

É crescente o número de investigações nas ciências do esporte que têm como temática principal a iniciação esportiva. Não obstante, para Silva, Fernandes e Celani (200 I), é ainda pequeno o número de estudos realizados especificamente com esporte para crianças e adolescentes. Podemos destacar dois principais focos para as pesquisas dessa área, as que objetivam um melhor desempenho atlético para o aprendiz e as que visam a prática esportiva como meio para o desenvolvimento integral e sadio de seus praticantes.

No Brasil, as pesquisas que envolvem crianças esportistas têm, na maioria dos casos, investigado esportes como o futebol, basquete, vôlei, natação e atletismo (RÉ; DE ROSE JÚNIOR; BÖHME, 2004; SIMÕES; BÖHME; LUCATO, 2001 ; SILVA; FERNANDES; CELANI, 200 I; ARENA; BÖHME, 2000; DE ROSE JÚNIOR; VASCONCELOS, 1997; SCAGLIA, 1996), havendo ainda um amplo campo de investigação em esportes menos populares.

É notável a complexidade e a impossibilidade de se estudar o esporte como um fenômeno único, tendo em vista as diferenças entre suas diversas modalidades, que vão desde os aspectos técnicos até os culturais. Desta forma, as demandas da iniciação seriam diferentes para cada esporte, onde um privilegiaria a técnica, outro a tática, outro as valências físicas, etc. As variadas idades recomendadas para a iniciação nos diferentes esportes é um exemplo de como as especificidades de cada modalidade devem ser consideradas (SILVA; FERNANDES; CELANI, 200I).

O esporte foco deste estudo é a vela, que se mostra como um esporte diferenciado, pois estabelece um grande envolvimento com a natureza, exige equipamentos específicos, um local onde haja espaço relativamente grande para 
navegação, instrutor com experiência no esporte, além de ser composto por uma série de movimentos não naturais (BAÑOS; SUÁREZ, 2006). Por essas peculiaridades, a vela não é um esporte comum à realidade brasileira tal como os esportes mais tradicionais como futebol, atletismo, dentre outros em que a criança se envolve com poucos ou sem materiais ou recursos e em espaços diversos. Sendo um esporte diferenciado, percebe-se que sua iniciação merece também investigações específicas, respeitando as suas características e considerando a complexidade da iniciação esportiva.

A vela é um dos esportes em que o Brasil se destaca no cenário internacional, e que mais trouxe medalhas olímpicas para o nosso país, porém a modalidade ainda carece de estudos científicos que deem suporte a sua prática em todos os níveis (BRANDT, 2008). Quando tratamos da iniciação no esporte não é diferente, pois pouco se sabe, além das próprias experiências vividas pelos velejadores, sobre como se dá essa iniciação no Brasil.

Apesar do considerável número de estudos, especialmente internacionais, que envolvem os esportes com vela (SEGATO et al., 20 l0; RUSCHEL et al., 2009; BRANDT, 2008; CASTAGNA; BRISSWALTER, 2007; CUNNINGHAM; HALE, 2007; SECULIC et al., 2006; ARAÚJO; DAVIDS; SERPA, 2005; WALLS; GALE, 200I), observamos uma lacuna científica a ser preenchida na iniciação da prática desse esporte, mesmo fora do Brasil. Alguns trabalhos são publicados, mas sem que haja rigor científico, apenas tratando de experiências de alguns profissionais. Tivemos acesso a apenas uma pesquisa relevante que tratava da prática de vela para jovens (DUARTE; MULKAY; PERÉZ, 2004), mas esta não trás contribuições para o processo de iniciação no esporte, pois se direciona ao rendimento e detecção de talentos.

Tendo em vista a escassez de estudos científicos que tratem da iniciação esportiva na vela, uma abordagem exploratória é necessária para que possamos conhecer quais as condições dessa iniciação no Brasil, e posteriormente investigar situações mais pontuais como a especialização na modalidade, os tipos de treinamento, dentre outros. Levando em consideração a problematização apresentada, o presente estudo tem por objetivo investigar a iniciação esportiva de velejadores brasileiros de alto rendimento.

\section{MÉTODO}

Trata-se de uma pesquisa de campo qualitativa de natureza exploratória, pois procura observar, analisar e descrever o fenômeno até então pouco estudado, a iniciação esportiva de velejadores brasileiros de alto rendimento. 
A coleta dos dados foi realizada em momento de competição nos meses de fevereiro e março de 2007 durante o Pré-Panamericano e Pré-Olímpico de vela realizados no Brasil. A entrevista foi realizada individualmente em local confortável e privado, de maneira que o participante tivesse liberdade para expressar sua história e opiniões. Foi esclarecido ao participante que ele poderia indicar o local de sua preferência para a coleta, caso não estivesse confortável no local proposto.

A seleção dos participantes foi do tipo não-probabilística intencional, selecionando por conveniência e disponibilidade dos velejadores participantes das competições citadas. Como sugere Turato (2005), a pesquisa qualitativa busca propositalmente os indivíduos que vivenciam o problema em foco e/ou têm conhecimento sobre ele. Com essa preocupação, foram selecionados treze atletas brasileiros que competem em nível internacional, sendo sete mulheres (idade $\bar{x}$ $=20$ anos) e seis homens (idade $\bar{x}=23$ anos) de diferentes classes. Todos os atletas foram esclarecidos quanto aos objetivos e procedimentos do estudo e demonstraram a aceitação por meio da assinatura do Termo de Consentimento Livre e Esclarecido. Uma das atletas era menor de dezoito anos, e por isso sua mãe assinou seu termo.

O instrumento utilizado na pesquisa foi uma entrevista do tipo semiestruturada. Para Selltiz, Wrightsman e Cook ( 1987) a entrevista semiestruturada é apropriada em pesquisas que envolvam a percepção, atitudes e opinião e também quando se está sondando uma nova área de investigação. Além de questões previamente definidas, a entrevista semiestruturada permite que se realizem explorações não previstas pelo pesquisador, oferecendo liberdade ao entrevistado para dissertar sobre o tema ou abordar aspectos que sejam relevantes sobre o que vivenciou (NEGRINE, 1999).

$\bigcirc$ roteiro de entrevista elaborado abordava variados temas pertinentes à vela, tendo em vista o pouco conhecimento teórico produzido sobre a prática deste esporte no Brasil. As questões ligadas ao tema "iniciação esportiva", abordado neste estudo, estavam incluídas no bloco sobre o histórico atlético. Duas questões gerais foram apresentadas neste momento aos participantes: "Fale sobre o seu histórico atlético." e "Como iniciou a prática da vela?". No roteiro de entrevista estavam listados outros pontos de interesse dos pesquisadores, questionados somente no caso de não serem abordados espontaneamente pelo velejador: "Por que escolheu a vela?", "Quando iniciou a prática da vela?", "Quando passou a competir em regatas?", e "Praticou alguma outra modalidade esportiva?". 
Os depoimentos foram registrados por meio de gravadores de voz digitais. Os mesmos foram transcritos e arquivados em forma de texto digitalizado para a facilitação das leituras.

A análise das entrevistas ocorreu seguindo alguns passos necessários para a organização coerente e lógica das informações, permitindo mais facilidade na visualização dos depoimentos. Realizada a primeira leitura de todos os depoimentos, foi possível perceber quatro categorias que deveriam ser aprofundadas e discutidas no presente estudo, são estas: o histórico atlético, os primeiros contatos com a vela, o prazer da prática e a iniciação em competições. Em seguida o texto foi relido detalhadamente, sendo identificados os microdiscursos, partes das falas das entrevistas que continham sentido e associação com as categorias anteriormente estabelecidas. A organização dos microdiscursos facilita a compreensão e análise dos conteúdos de cada categoria, e possibilita a elaboração dos quadros resumo (ANDRADE, 200 I). O quadro resumo, proposto por Andrade (200 I), permitiu uma visualização mais clara e útil dos dados do grupo, possibilitando observar a totalidade das percepções declaradas e uma sintetização mais objetiva de um volume bastante extenso de informações contidas nas entrevistas brutas e nas matrizes individuais.

Em algumas situações foi necessária a comparação entre grupos que apresentaram características diferentes. Nesses casos, foi utilizada a Técnica do Espelho (ANDRADE, 200I), que significa colocar "lado a lado" os conteúdos mais importantes dos depoimentos, na forma dos microdiscursos. $\bigcirc$ objetivo deste método é permitir comparações e análises qualitativas mais aprofundadas de uma realidade investigada.

Para a diferenciação entre os discursos de cada participante, os mesmos serão identificados no texto com as letras M ou F, que indicam o sexo masculino ou feminino, seguidos do número que identifica a ordem cronológica em que as entrevistas foram realizadas. Ex.: MI (primeiro atleta masculino entrevistado); F3 (terceira atleta feminina entrevistada).

\section{APRESENTAÇÃO E DISCUSSÃO DOS RESULTADOS}

Apresentaremos separadamente os resultados de cada categoria estabelecida e suas respectivas discussões. $\bigcirc$ texto é estruturado da seguinte forma: apresentação do quadro resumo com as informações da categoria em estudo, comentários sobre este e apresentação de alguns dos microdiscursos mais relevantes, seguidos das discussões cabíveis. 


\section{HISTÓRICO ATLÉTICO/ESPORTIVO:}

Quadro I. Histórico atlético e esportivo dos velejadores participantes.

\begin{tabular}{|l|}
\hline \multicolumn{1}{|c|}{ Histórico atlético e esportivo dos velejadores } \\
\hline Gosto pela prática esportiva desde a infância. \\
\hline Prática variada de esportes: individuais, coletivos, aquáticos, terrestres, etc. \\
\hline Prática de esportes pouco populares: hipismo, hóquei, tênis, etc. \\
\hline Personalidade competitiva, havendo procura por práticas esportivas em que a vitória fosse mais acessível. \\
\hline Gosto pela Educação Física na escola. \\
\hline Alguns chegaram ao nível competitivo também em outros esportes. \\
\hline
\end{tabular}

Os participantes da pesquisa, em sua maioria, relataram ter praticado no período da infância uma grande variedade de esportes, além da prática da vela. É possível verificar essa característica no depoimento de M6 "Eu sempre era o polivalente... Sempre fui um cara que tive ligação com o esporte desde pequeno" e MI "Desde pequena eu faço natação... Fiz hipismo, jogava futebol na escola, vôlei...". Esses esportes são dos mais variados, existindo desde a prática de modalidades mais comuns, como futebol e vôlei, até esportes considerados elitizados para a realidade brasileira, como o hipismo e o tênis. Essa busca pela prática esportiva evidencia a personalidade competitiva desses velejadores, que parecem sempre estar buscando a prática esportiva. Essa característica competitiva é percebida também nos depoimentos de $\mathrm{MI}$ " $\mathrm{Eu}$ sempre fui bastante competitivo", FI "Eu sempre sou muito competitiva... em tudo, em qualquer coisa" e M4 "O que mais motiva... a competição. Eu sou um cara competitivo".

A escola foi um importante espaço de prática esportiva para os velejadores, verificado em diversos momentos de seus depoimentos. Há de se destacar, ainda, o interesse de alguns pelas aulas de Educação Física na escola, como relatado por M2 "Nas aulas de Educação Física no colégio eu sempre fui bastante participativo. Seja qual fosse a atividade: futebol, vôlei, enfim".

As condições destacadas pelos atletas brasileiros da vela são apontadas pela literatura científica como ideais para a iniciação da criança no mundo dos esportes. Os pesquisadores têm sugerido que a participação da criança em diversas atividades esportivas é mais benéfica do que expô-la prematuramente a aprender uma 
destreza particular ou especializada em um esporte antes que esteja integralmente desenvolvida (KREBS, 1992; MIROTTI; CASASNOVAS, 2003).

Segundo Freire (200I), ao final de um longo processo, o acervo de possibilidades motoras, intelectuais, sociais e morais disponível no jovem que teve uma formação esportiva ampla será mais completo do que no jovem formado em um sistema especializado. Há que se considerar ainda o destacado por Ramos e Neves (2008), para os quais a especialização precoce, caracterizada pela especialização em um determinado esporte mais cedo que a idade apropriada para tal, pode trazer como consequência o abandono prematuro da prática esportiva. Essa iniciação diversificada não seria importante apenas para um desenvolvimento infantil mais adequado, sem acarretar em prejuízos físicos ou psicológicos, mas também para que se tenha uma carreira esportiva mais promissora, obtendo melhores resultados futuros.

Segundo a Teoria da Especialização Motora, apresentada inicialmente no ano de 1992 por Krebs (1992), a diversificação esportiva é importante para ampliar o repertório motor dos praticantes antes da fase de especialização, que é a última das quatro fases do modelo, e deve ser precedida das fases de estimulação, aprendizagem e prática. Desta forma, a variabilidade de práticas esportivas relatadas pelos velejadores participantes parece ser um fator que contribuiu positivamente para o sucesso na carreira desses atletas. Para Zakharov e Gomes apud Sukamoto e Nunomura (2005), atletas campeões na categoria adulta nem sempre obtiveram bons resultados nas categorias inferiores, demonstrando que a ideia de que "quanto mais cedo iniciar melhor" não necessariamente é verdadeira. Além da pergunta que naturalmente surge quando se pensa na iniciação esportiva infantil - quando começar? - é fundamental que se questione principalmente "como começar?".

Percebemos ainda que alguns participantes chegaram ao nível competitivo também em outros esportes. Essa característica pôde ser observada nos depoimentos de F2 "Já pratiquei tênis, competindo" e F6 "Joguei vôlei, fui federada". 
Quadro 2. Primeiros contatos dos participantes com a vela.

\begin{tabular}{|ll|}
\hline \multicolumn{2}{|c|}{ Primeiros contatos com a vela } \\
\hline $\begin{array}{l}\text { Velejadores com histórico familiar de prática de } \\
\text { vela }\end{array}$ & $\begin{array}{l}\text { Velejadores sem histórico familiar de } \\
\text { prática de vela }\end{array}$ \\
\hline $\begin{array}{l}\text { Histórico familiar de velejadores, } \\
\text { competitivos ou não. }\end{array}$ & $\begin{array}{l}\text { Famílias sem histórico de prática de vela, } \\
\text { mas que praticam ou praticaram outras } \\
\text { modalidades esportivas. }\end{array}$ \\
\hline $\begin{array}{l}\text { Iniciação da prática como forma de lazer, na } \\
\text { maioria dos casos com a própria família. }\end{array}$ & $\begin{array}{l}\text { Iniciação em escolinhas de vela. } \\
\text { Apoio dos pais e família para iniciação e } \\
\text { permanência na prática da vela. }\end{array}$ \\
\hline $\begin{array}{l}\text { Iniciação com idades de } 5 \text { a } 9 \text { anos. } \\
\text { permanência na prática da vela. }\end{array}$ \\
\hline $\begin{array}{l}\text { Oportunidade de prática por haver espaços } \\
\text { adequados em sua cidade ou região. }\end{array}$
\end{tabular}

Observa-se que grande parte dos entrevistados iniciou na vela por influência da família. Na maioria dos casos, oito participantes, acompanhavam os pais nas navegações ou outros membros da família que eram velejadores, competidores ou não. Por outro lado, existem participantes que não tinham em sua família um histórico de velejadores, mas outras oportunidades foram essenciais para a iniciação da prática. Devido a essas diferentes características, optamos por dividir a apresentação dos resultados diferenciando e comparando os grupos de quem tem e quem não tem histórico de velejadores na família.

Embora alguns velejadores não tenham familiares que praticavam a vela, o apoio familiar para a carreira foi percebido nos depoimentos de todos os velejadores. Pesquisas têm apontado que o suporte social, principalmente dos pais, é um dos principais responsáveis pela entrada e permanência de crianças e adolescentes na prática esportiva (KREBS et al., 2008; MCGEE et al., 2006). 
Segundo Bloom apud Moraes, Rabelo e Salmela (2004), nos anos iniciais, os pais servem de exemplo para a iniciação no domínio específico, estimulando e criando situações de interesse para os filhos, o que parece ser o caso dos velejadores brasileiros. Podemos destacar os microdiscursos dos participantes M3 "Eu comecei com sete anos, meu pai era velejador. E foi ele que me botou no esporte" e F3 "O meu pai sempre me incentivou à vela, desde pequena" que tinham familiares velejadores, e M6 "O meu pai e minha mãe sempre apoiaram bastante nesta trajetória" e M5 "Eu fui influenciado pelos meus pais. Minha família não tem nenhum histórico de vela, mas eles frequentavam o clube... e me botaram a velejar" que não tinham familiares velejadores, para demonstrar o apoio dos pais na prática da vela.

Se por um lado a família incentiva a entrada e permanência da criança no esporte, por outro também pode apresentar aspectos negativos no desenvolvimento da criança esportista, quando não envolvidas de maneira adequada. A alta exigência e cobrança dos pais pode desenvolver uma atmosfera de regras rígidas e expectativas irreais (VILANI; SAMULSKI, 2002), o que seria o superenvolvimento dos pais na prática. Analisando os discursos dos entrevistados, não pareceu haver exageros em estímulos para a iniciação na vela por parte dos pais, apesar da vontade de alguns para que o filho fosse um velejador competitivo.

fato de, para grande parte dos participantes, a iniciação ter ocorrido em meio ao ambiente familiar, faz com que o início da prática da vela se dê, de maneira geral, bastante cedo. Para os participantes sem histórico familiar de velejadores, que iniciaram em escolinhas de vela, a idade foi pouco mais avançada, chegando aos treze anos. Segundo Tsukamoto e Nunomura (2005), o processo de iniciação esportiva poderia ser iniciado aproximadamente aos seis anos, com a prática de modalidades variadas. Existe divergência na literatura quanto à recomendação da idade mais apropriada para a iniciação da vela, variando de sete a nove anos de idades para Fernandes e Freitas (2007) e Gomes (2002), respectivamente. Porém, os autores convergem no ponto em que a iniciação deve ser genérica e adaptada para as condições de desenvolvimento das crianças, não havendo uma especialização precoce, como anteriormente discutido.

Percebe-se que a iniciação à prática da vela, em alguns casos, ocorreu em idade inferior às recomendadas. Gabarra, Rubio e Ângelo (2009) destacam Sanchez para afirmar que o esporte não possui virtudes inerentes; não é naturalmente bom ou mau, mas depende do modo como é conduzido. Para Lavoura e Machado (2008), afirmações como "esporte é saúde" e "o esporte educa" nem sempre são 
verdadeiras, pois dependem das intenções, valores, posturas e condutas adotadas pelas pessoas envolvidas no contexto esportivo. No caso da prática durante a infância esse pressuposto é fundamental, pois geralmente há mediação de um adulto que deve estar atento para que o momento privilegie o desenvolvimento integral da criança por meio de uma prática prazerosa. Por tratar-se de um momento familiar de lazer, e não de treinamento, esse tipo de prática não pareceu prejudicial segundo os depoimentos dos participantes, como relatado por M2 "Comecei a velejar no barco dos meus pais, que era um barco oceânico... com cinco anos de idade. Tinham um barco como lazer, não corriam regata".

Não havendo influência da família, é importante que outras oportunidades existam para que as crianças iniciem no iatismo. $O$ estudo de Krebs et al. (2008) demonstrou essa importância do contexto, ao verificar que a maior parte dos tenistas jovens atribuem sua disposição para iniciar no esporte ao fato de estarem participando ativamente do contexto do tênis na infância. No caso da vela, essas oportunidades que podem provir de iniciativas públicas ou privadas, na forma de escolinhas, por exemplo, pouco são encontradas no Brasil. Das que existem, com exceção de poucos projetos de cunho social, a maioria apresenta grande custo financeiro para a participação, além de serem realizadas em poucas cidades brasileiras. São diversos os locais possíveis de prática da vela, e esses locais, como lagos e represas, que não ocorrem apenas no litoral, devem ser melhor explorados. Oportunidades como a que teve a velejadora F4 "Eu estava jogando na lagoa, daí encontrei um Catamarã da prefeitura e fui ver o que era. Descobri que era uma escolinha de vela e decidi entrar pra ver qual que era", são essenciais, em especial para a maior parte da população que tem pouca condição de frequentar clubes onde haja a prática de vela.

A preocupação de expansão de oportunidades não é apenas social, mas também importante para a própria vela brasileira. Considerando a importância olímpica da modalidade para o nosso país, não é aconselhável que se aguarde o surgimento de novos fenômenos esportivos isoladamente. Um projeto para disseminar a prática da vela pelas diferentes regiões brasileiras seria uma possibilidade para a manutenção do Brasil como uma das mais importantes escolas de vela do mundo. 


\section{O PRAZER DA PRÁTICA DA VELA NA INICIAÇÃO:}

Quadro 3. Prazer da prática da vela na iniciação dos velejadores

\begin{tabular}{|c|c|}
\hline \multicolumn{2}{|c|}{$\begin{array}{l}\text { O prazer da prática da vela durante a iniciação } \\
\text { (características comuns aos velejadores) }\end{array}$} \\
\hline \multicolumn{2}{|l|}{ Prazer por práticas esportivas diversas. } \\
\hline \multicolumn{2}{|c|}{ Gosto pela prática da vela devido ao contato com a natureza. } \\
\hline \multicolumn{2}{|c|}{ Prática na iniciação voltada ao lazer. Prazer em velejar. } \\
\hline \multicolumn{2}{|c|}{ Oportunidade para fazer amizades e encontrar os amigos. } \\
\hline Velejadores que sempre gostaram de velejar & $\begin{array}{l}\text { Velejadores que no início não gostavam de } \\
\text { velejar }\end{array}$ \\
\hline Prazer pelo passeio a barco e treinamento. & $\begin{array}{l}\text { Prazer pelo passeio a barco, mas não pelo } \\
\text { treinamento. }\end{array}$ \\
\hline Gosto pelo mar. & $\begin{array}{l}\text { Gosto pelo mar, porém desgosto pela polui- } \\
\text { ção da água no local de prática. }\end{array}$ \\
\hline & $\begin{array}{l}\text { Todos vieram a gostar da prática da vela } \\
\text { posteriormente à iniciação. }\end{array}$ \\
\hline
\end{tabular}

Quanto ao prazer da prática da vela, a maioria dos relatos indica o gosto pela prática desde a sua iniciação - F2: "Eu desde pequena sou fascinada por velejar, eu gosto muito, me da muito prazer velejar". Essa característica faz com que grande parte dos velejadores tenha iniciado a sua prática ainda como forma de lazer, especialmente entre aqueles em que a família já velejava. Por outro lado, houve situações (2 casos) em que os velejadores não iniciaram a prática por vontade própria, mas adquiriram o gosto com o passar do tempo. Esse fato fez com que algumas comparações entre esses dois diferentes grupos fossem realizadas (Quadro 3).

Podemos identificar características comuns aos participantes da pesquisa em relação ao prazer de velejar. O contato com a natureza e o gosto pelo mar é um fator bastante importante para os velejadores, como podemos observar nos depoimentos de M2 "Eu fui levado (a velejar) meio que por gosto e vontade. E por gostar muito do mar e da vela mesmo" e FI "...acho que pelo contato com a natureza...". Por outro lado, apesar do gosto pelo mar, um dos motivos que constrangia a prática de um dos velejadores era a preocupação com a poluição do local de treinamento - MI "No começo eu não gostava... A... (local de prática) é meio nojento né?". 
Outra característica a se destacar é o local de prática da vela como uma possibilidade de fazer amizades e encontrar os amigos. Essa particularidade atribuída aos esportes, de fazedor de amizades, é destacada no depoimento de MI, um praticante que não gostava de velejar, mas que por causa das amizades que fez em sua escolinha de vela acabou optando por continuar: "...eu comecei a fazer uns amigos e comecei a gostar de velejar".

Outro caso importante de ser destacado, relatado por apenas um dos participantes mas não desprezível de discussão, é o gosto pelo velejar como forma de lazer, mas não pelo treinamento - M3 "No começo eu não gostava muito de velejar. Eu gostava de passear". Esse depoimento demonstra a indissociabilidade da iniciação esportiva infantil com o prazer na prática. Segundo Serpa (2003), a literatura sobre os motivos para participação de crianças e jovens no esporte é consistente em assinalar o divertimento como essencial. Para o autor, o trabalho com crianças e jovens deve ser ligado ao lúdico, e é uma visão errônea a transformação das atividades lúdicas em uma perspectiva de trabalho e obrigação já nos primeiros anos.

Enquanto muitos persistem em antecipar a especialização no esporte e normatizá-la de forma rígida e sistêmica, tendências essas que são observadas em vários países (MARQUES; OLIVEIRA, 200 I), nossos resultados trazem um importante ponto a ser discutido a esse respeito no contexto da vela. $O$ fato da maioria de nossos atletas terem iniciado a prática da vela de maneira lúdica e prazerosa, e terem chegado ao alto rendimento, participando de uma competição Pré-Panamericana ou Pré-Olímpica, mostra que mesmo quando se busca o rendimento a ludicidade é um fator que não necessariamente deve ser desprezada dentro do esporte. Sendo o lúdico um elemento que auxilia na manutenção da criança dentro do esporte (SERPA, 2003; WUERTH; LEE; ALFERMANN, 2004) e que, em nosso caso da vela, parece ser um fator importante para o desempenho futuro dos desportistas, parece não haver motivos para a sua exclusão do processo de iniciação. $\bigcirc$ estudo de Davies (2006) reforça essa posição, pois o autor observou que os alunos considerados melhores velejadores de uma escolinha de vela eram justamente aqueles que mais se divertiam nas aulas.

A vinculação do esporte ao profissionalismo competitivo o tem distanciado cada vez mais de sua essência lúdica, descaracterizando-o. Segundo Neuenfeldt (2005), a tendência é que a criança acabe por incorporar esse modelo de esporte como ideal, deixando de vê-lo como uma manifestação lúdica. Considerando a importância que tem a competição no esporte atual, em seguida apresentamos os resultados da última categoria investigada, a iniciação nas competições de vela. 


\section{A INICIAÇÃO NAS COMPETIÇÕES:}

Quadro 4. Iniciação dos velejadores em competições

\begin{tabular}{|l|}
\hline \multicolumn{1}{|c|}{ A iniciação nas competições } \\
\hline Participação em competições, na maioria dos casos ainda no primeiro ano de aprendiz.* \\
\hline Início em competições da classe Optmist. \\
\hline Participações na maioria dos casos vitoriosas. \\
\hline A participação em competições parece ter sido positiva do ponto de vista psicológico. \\
\hline
\end{tabular}

* Interpretamos aqui o primeiro ano de aprendiz a partir do momento da prática sistematizada, e não da prática de lazer familiar.

Devido à prática da vela ser realizada como forma de lazer familiar desde os primeiros anos de vida de alguns dos velejadores, é complexo o estabelecimento do tempo de prática da vela antes da iniciação nas competições. Por isso, o critério estabelecido foi o tempo decorrido entre o início da prática sistematizada e a iniciação em competições, para que houvesse uma padronização. Assim, observou-se que as competições de vela se iniciaram cedo para os participantes da pesquisa, na maioria dos casos ainda no primeiro ano de prática sistematizada. Podemos visualizar essa característica nos discursos de F4 "Eu fui muito bem sucedida no ano de estreante, ganhei várias regatas", M6 "Foi desde de pequeno porque tem a escolinha de vela... e sempre tem as regatas do próprio clube" e M5 "Eu comecei a velejar com dez anos na classe Optimist. Comecei na escola de vela... e com onze anos eu comecei a competir...". Há de se considerar a qualidade, e possível potencial, de nossos velejadores, o que fez com que estes se destacassem e mais precocemente participassem de competições.

A classe de iniciação nas competições dos atletas da pesquisa, a Optimist, é considerada própria para a idade e é normalmente a utilizada na iniciação do iatismo até os quinze anos de idade (geralmente depois dos quinze se aprende no Dingue) (DAVIES, 2006). A classe Optimist é apropriada para a iniciação infantil na vela devido as suas características que se ajustam tanto aos aspectos físicos da criança quanto aos aspectos técnicos, devido às poucas regulagens do barco.

A competição esportiva infantil faz parte da prática da maioria dos esportes na atualidade. $O$ tema provoca controvérsias na literatura, e tem sido estudado tanto sob a perspectiva biológica/física (AMATO, 2000; LAM, 2005; JOHNSON et al., 
2005) quanto psicológica (DE ROSE JÚNIOR; VASCONCELLOS, I997; RÉ; DE ROSE JÚNIOR; BÖHME, 2004). Alguns autores defendem essa prática, enquanto outros a condenam e acreditam que o esporte perdeu seu sentido de ludicidade e espontaneidade, passando a tratar-se apenas da valorização do resultado.

Além da descaracterização imposta ao esporte, alguns autores alertam também para os prejuízos que a competição pode trazer à criança quando não bem administrada. O estresse, entre os aspectos psicológicos existentes na competição infantil, segundo Ré, De Rose Júnior e Böhme (2004), é um dos mais marcantes e talvez a principal justificativa para críticas negativas daqueles que se contrapõe à competição infantil. Por outro lado, para os mesmos autores, existe a hipótese de que crianças que se destacam estão menos suscetíveis e também conseguem gerenciar melhor as situações causadoras de estresse, sendo esta capacidade importante para o seu desempenho futuro.

Opiniões mais ponderadas indicam de forma coerente e lógica como esse processo deve ser introduzido na vida do atleta infanto-juvenil (DE ROSE JÚNIOR; VASCONCELLOS, 1997). Como Lavoura e Machado (2008), que destacam pontos positivos da competição esportiva na infância:

...a competição nesta fase deveria ser encarada como um momento de conhecimento e autoavaliação do próprio indivíduo, como um fator de motivação e de espaço para novas amizades e aumento do círculo social e da ação comunicativa, com pessoas de outras associações, outros clubes, de outras regiões e cidades (LAVOURA; MACHADO, 2008, p. I 53).

Observa-se no depoimento a seguir o quanto a competição pode interferir na realidade dos atletas, inclusive no prazer da prática esportiva: F2 "Às vezes a gente ta treinando todo dia, todo dia... e eu acabo esquecendo de como eu gosto de velejar".

Em nosso caso, os velejadores demonstraram que a competição ocorreu ao natural, sem que houvesse pressões da parte de técnicos ou pais. Vale considerar que tratamos de atletas bem sucedidos dentro da vela. É importante que se destaque a participação das crianças que não se saíram tão bem nestas competições pode não ter sido tão proveitosa. A relação entre a vitória no esporte e a aderência é demonstrada no depoimento de FI, que devido aos seus resultados positivos permaneceu praticando a vela: "De todos esses esportes os meus preferidos são a vela e o tênis. Só que como na vela eu ganhava mais competições...".

\section{CONSIDERAÇÕES FINAIS}

A prática esportiva dos velejadores participantes foi diversificada durante a juventude, pois existem participações em esportes com diferentes características, 
chegando alguns atletas ao nível competitivo também em outras modalidades. Esses resultados sugerem que de maneira geral não houve especialização precoce na vela, o que pode ser um fator positivo para que tenham alcançado o alto nível esportivo neste esporte, ao ponto de participarem de importantes competições como o Pré-Panamericano e o Pré-Olímpico.

A prática da vela recebeu influência da família na maioria dos casos. Esta se deu diretamente, por meio do apoio à prática, ou indiretamente, pela existência de outros familiares que já velejavam. Embora a literatura corrobore com esses resultados ao apontar a família como uma importante incentivadora da prática esportiva, quando exercem pressões demasiadas para que a criança ou o adolescente pratique esportes os familiares podem estar promovendo um ambiente prejudicial. No caso aqui investigado, entende-se que as influências não foram exacerbadas, pois o prazer ao velejar esteve presente nos discursos, demonstrando a espontaneidade dos participantes.

As competições passaram a fazer parte da vida dos velejadores ainda cedo. A maior parte relatou que no primeiro ano de prática já teria participado de regatas, porém esta precocidade não pareceu prejudicial a estes velejadores. É importante se destacar que estes são atletas bem sucedidos, e que o bom desenvolvimento de suas habilidades desde a infância pode ter influência na sua atual avaliação positiva sobre as primeiras competições. Portanto, é necessário contextualizar nossos resultados para que não sirvam de justificativa para a participação precoce de crianças em competições.

Finalizando o presente estudo, por sua característica diagnóstica é possível sugerir novas investigações sobre a iniciação esportiva na vela. Devido à iniciação da maior parte dos participantes entrevistados ter ocorrido há pouco mais uma década, é relevante pesquisar de que forma é dada atualmente a iniciação da vela no Brasil. Investigar quais as regiões onde existem as escolas de vela, qual a população atingida, e qual o perfil do aprendiz e suas características socioculturais podem ser bons temas de pesquisa para um esporte ainda carente de produção científica nacional. A investigação do contexto das crianças iniciantes na prática da vela também é um elemento que se evidencia a partir dos presentes resultados, considerando a influência da família na iniciação e do envolvimento dos atletas no ambiente da vela mesmo antes da sua prática. Tais resultados podem subsidiar tanto a prática dos professores que trabalham com a vela quanto à própria gerência da modalidade, visando ampliar a sua disponibilidade para uma maior parcela da população. 


\section{Sporting initiation of brazilian sailors: a diagnoses qualitative study}

ABSTRACT: This research investigated the sporting initiation of Brazilian sailors. Participated of the study 13 sailors of high level, participants of the Pré-Panamericano and Pré-Olympic of sail. The used instrument was a semi-structured interview. The results showed that the athletes had varied sport experiences during childhood, besides the own practice of the sailor. The initiation in the sail felt in most of the cases through the influence of the family, that were or still are sailors. The practice in the initiation was considered pleased for most of the sailor. Some told that they began early in the competitions, but that fact didn't seem to have harmed psychological in the sporting development of these along they career.

KEYWORDS: Sports; athletic performance; qualitative research; interview.

\section{La iniciación deportiva en velejadores brasileiros: um estudio diagnostico cualitativo}

RESUMEN: Fue investigado la iniciación deportiva en velejadores brasileños. Participaron en el estúdio 13 velejadores del alto nível, participantes del Pré-Panamericano y Pré-Olimpíaco de vela. El instrumento usado fue una entrevista semi-estructurada. Los resultados mostraban que los atletas adquiriran experiencias deportivas en la infancia, además de la própria práctica de la vela. La iniciación en la vela en la mayoría de las cajas a través de la influencia de la familia, ése lo fue o todavia eran velejadores. La práctica en la iniciación fue considerada prazeirosa para la mayor parte de los velejadores. Algunos informam empezar temprano em lãs competiciones, pero eso no daño psicologicamente tan poço El desarrollo deportivo haber que el hecho no seem haber dañado psicologicamente o en el desarrollo deportivo al largo de su carrera.

PALABRAS CLAVE: Deportes; rendimiento atlético; pesquisa cualitativa; entrevista.

\section{REFERÊNCIAS}

AMATO, R. Deporte competitivo infanto juvenil: ipromoción de la salud o situación de riesgo?. Adolescencia Latinoamericana, Porto Alegre, v. 2, n. I, p. 09- I5, 2000.

ANDRADE, A. Ocorrência e controle subjetivo do stress na percepção de bancários ativos e sedentários: a importância do sujeito da relação "atividade física e saúde". 200 I. 389 f. 2 v. Tese (Doutorado em Engenharia de Produção) - Universidade Federal de Santa Catarina, Florianópolis, 2001.

ARAÚJO, D; DAVIDS, K; SERPA, S. An ecological approach to expertise effects in decisionmaking in a simulated sailing regatta. Psychology of Sport and Exercise, Amsterdam, v. 6, n. 6, p. 67I-692, 2005.

ARENA, S. S; BÖHME, M. T. S. Programas de iniciação e especialização esportiva na grande São Paulo. Revista Paulista de Educação Física, São Paulo, v. I4, n. 2, p. I 84- 195, 2000. 
BAÑOS, V. M; SUÁREZ, A. D. La vela, una actividad extraescolar alternativa en los centros docentes. Lecturas: Educación Física y Deportes, Buenos Aires, n. I I, out. 2006. Disponível em: <http://www.efdeportes.com>. Acesso em: I0 jul. 2007.

BRANDT, R. Estados de humor de atletas da Seleção Brasileira de Vela nos Jogos Pan-Americanos. 2008. 135. Dissertação (Mestrado em Ciências do Movimento Humano) - Universidade do Estado de Santa Catarina, Florianópolis, 2008.

CASTAGNA, O; BRISSWALTER, J. Assessment of energy demand in Laser sailing: influences of exercise duration and performance level. European Journal of Applied Physiology, Nova York, v. 99, n. 2, p. 95-101, 2007.

CUNNINGHAM, P; HALE, T. Physiological responses of elite Laser sailors to 30 minutes of simulated upwind sailing. Journal of Sport Science, Londres, v. 25, n. 10, p. I 109- I | |6, 2007.

DAVIES, J. A. latismo e profissionalização: um estudo etnográfico do Projeto Grael. Esporte e Sociedade, n. 4, nov. 2006. Disponível em: <http://www.lazer.eefd.ufrj.br/espsoc>. Acesso em: 13 jul. 2007.

DE ROSE JÚNIOR, D; VASCONCELLOS, E. G. Ansiedade-traço competitiva e atletismo: um estudo com atletas infanto-juvenil. Revista Paulista de Educação Física, São Paulo, v. I I, n. 2, p. 148-54, 1997.

DUARTE, R. B; MULKAY, I. Z; PÉREZ, L. C. Valoración de parámetros psicosociales en la selección de talentos para el deporte de velas. Lecturas: Educación Física y Deportes, Buenos Aires, n. 73, jun. 2004. Disponível em: <http://www.efdeportes.com>. Acesso em: 22 abr. 2007.

FERNANDES, R. M; FREITAS, A. M. Esporte a vela e a Educação Física. Revista Lecturas: Educación Física y Deportes, Buenos Aires, n. 102, nov. 2006. Disponível em: <http://www. efdeportes.com >. Acesso em: 01 mai. 2007.

FREIRE, J. B. Especialização precoce no esporte, 16 jun. 2001 . Disponível em: <http://www. decorpointeiro.com.br >. Acesso em: 30 abr. 2007.

GABARRA, L. M; RUBIO, K; ANGELO, L. F. A Psicologia do Esporte na iniciação infantil. Psicología para América Latina, São Paulo, v. 18, 2009. Disponível em: < http://psicolatina. org/l8/esporte.html>. Acesso em: 03 set. 2010.

GOMES, A. C. Treinamento desportivo: estruturação e periodização. Porto Alegre: Artmed, 2002.

JOHNSON, B. et al. A need for reevaluation of sports participation recommendations for children with a solitary kidney. The Journal of Urology, Nova York, v. 174, n. 2, p. 686-689, 2005. 
KREBS, R. J. Da estimulação à especialização: primeiro esboço de uma teoria da especialização motora. Kinesis, Santa Maria,v. 9, p. 29-44, 1992.

KREBS, R. J. et al. Disposições pessoais de tenistas jovens: um estudo fundamentado na teoria bioecológica de Bronfenbrenner. Revista Brasileira de Psicologia do Esporte, São Paulo, v. 2, n. 2, p. I-24, 2008.

LAM, L. T. Hospitalisation due to sports-related injuries among children and adolescents in New South Wales, Australia: An analysis on socioeconomic and geographic differences. Journal of Science and Medicine in Sport, Mitchell, v. 8, n. 4, p. 433-440, dez. 2005.

LAVOURA, T. N; MACHADO, A. A. Especialização precoce: a importância do lúdico na iniciação esportiva. In: MACHADO, A. A. Especialização esportiva precoce. Jundiaí: Fontoura, 2008. p. |49-164.

MARQUES, A. T; OLIVEIRA, J. M. O treino dos jovens desportistas. Actualização de alguns temas que fazem a agenda do debate sobre a preparação dos mais jovens. Revista Portuguesa de Ciências do Desporto, Porto, v. I, n. I, p. 130-137, 2001.

MCGEE, R. et al. Participation in clubs and groups from childhood to adolescence and its effects on attachment and self-esteem. Journal of Adolescence, Londes, v. 29, n. I, p. I- 17, 2006.

MIROTTI, Z. S; CASASNOVAS, O. Edad de iniciación deportiva: optimo momento psicofísico. Archivos Argentinos del Pediatria, Buenos Aires, v. I0I, n. 4, p. 296-31 I, 2003.

MORAES, L. C; RABELO, A. S; SALMELA, J. H. Papel dos pais no desenvolvimento de jovens futebolistas. Psicologia: Reflexão e Crítica, Porto Alegre, v. 17, n. 2, p. 2 I I-222, 2004.

NEGRINI, A. Instrumentos de coleta de informações na pesquisa qualitativa. In: MOLINA NETO, V; TRIVIÑOS, A. N. S. A pesquisa qualitativa em Educação Física. Porto Alegre: UFRGS/SULINA, 1999. p. 61-93.

NEUENFELDT, D. L. O resgate do elemento lúdico no esporte: uma reeducação esportiva para o homem do terceiro milênio. Ação \& Movimento, São Paulo, v. 2, n. 3 , p. $164-170,2005$.

RAMOS, A. M; NEVES, R. L. R. A iniciação esportiva e a especialização precoce à luz da teoria da complexidade - notas introdutórias. Pensar a Prática, Goiânia, v. I I, n. I, p. I-8, 2008. Disponível em: <http://www.revistas.ufg.br/index.php/fef/article/viewArticle/I 786/3339>. Acessada em: 08 set. 2010.

RÉ, H. N; DE ROSE JÚNIOR, D; BÖHME, M. T, S. Stress e nível competitivo: considerações sobre jovens praticantes de futsal. Revista Brasileira de Ciência e Movimento, Brasília, v. I2, n. 4, p. 83-87, 2004.

RUSCHEL, C. et al. Incidência de lesões em velejadores brasileiros de diferentes níveis técnicos. Revista Brasileira de Medicina do Esporte, Niterói, v. I5, n. 4, p. 268-27I, 2009. 
SCAGLIA, A. J. Escolinha de futebol: uma questão pedagógica. Motriz, Rio Claro, v. 2, n. I, p. 36-43, 1996.

SECULIC, D. et al. EMG analysis of muscle load during simulation of characteristic postures in dinghy sailing. The Journal of Sports Medicine and Physical Fitness, Turin, v. 46, n. I, p. 20-27, 2006.

SEGATO, L. et al. Estresse psicológico de velejadores de alto nível esportivo em competição. Motricidade, Santa Maria da Feira, v. 6, n. 3, p. 53-62, 2010.

SELLTIZ; WRIGHTSMAN; COOK. Métodos de pesquisa nas relações sociais. São Paulo: E.P.U., 1987, v. 2.

SERPA, S. Treinar jovens: complexidade, exigência e responsabilidade. Revista da Educação Física, Maringá, v. 14, n. I, p. 75-82, 2003.

SILVA, F. M; FERNANDES, L; CELANI, F. O. Desporto de crianças e jovens - um estudo sobre as idades de iniciação. Revista Portuguesa de Ciências do Desporto, Porto, v. I, n. 2, p. 45-55, 200 I.

SIMÕES, A. C; BÖHME, M. T. S; LUCATO, S. A participação dos pais na vida esportiva dos filhos. Revista Paulista de Educação Física, São Paulo, v. 13, n. I, p. 34-45, 1999.

TSUKAMOTO, M. H. C; NUNOMURA, M. Iniciação esportiva e infância: um olhar sobre a ginástica artística. Revista Brasileira de Ciências do Esporte, Campinas, v. 26, n. 3, p. I59- I76, 2005.

TURATO, E. R. Métodos qualitativos e quantitativos na área da saúde: definições, diferenças e seus objetos de pesquisa. Revista de Saúde Pública, São Paulo, v. 39, n. 3, p. 507-5 |4, 2005.

VILANI, L. H. P; SAMULSKI, D. M. Família e esporte: uma revisão sobre a influencia dos pais na carreira esportiva de crianças e adolescentes. In: GARCIA, E. S; LEMOS, K. L. M. Temas atuais VII: Educação Física e Esporte. Belo Horizonte: Health, 2002. p. 09-26.

WALLS, J .T; GALE, T. J. A technique for the assessment of sailboard harness line force. Journal of Science and Medicine in Sport, Mitchell ,v. 4, n. 3, p. 348-356, 200 I.

WUERTH, S; LEE, M. J; ALFERMANN, D. Parental involvement and athletes career in youth sport. Psychology of Sport and Exercise, Amsterdam, v. 5, p. 2 I-33, 2004.

Endereço para correspondência: Recebido: 23 maio 2009 Aprovado: 24 setembro 2010 Maick da Silveira Viana Centro de Ciências da Saúde e do Esporte Laboratório de Psicologia do Esporte e do Exercício Rua Pascoal Simone, 358 - Coqueiros Florianópolis-SC CEP: $88080-350$ 